\title{
Deformation and Recrystallization of a Jewellery White Gold Alloy
}

\author{
Maria Rosa Pinasco and Enrica Stagno \\ Laboratorio di Metallurgia e Metallografia, Università degli Studi di Genova, Genoa \\ in association with Gori \& Zucchi, S.p.A., Arezzo, Italy
}

\begin{abstract}
Most nickel-containing white gold alloys are susceptible to phase separation and excessive hardening when annealed during fabrication. This article shows how basic metallurgical principles may be applied in seeking to define, for a specific alloy, an annealing schedule which will yield structures suitable for cold-working.
\end{abstract}

The manufacture of jewellery articles from gold alloys initially cast in ingot form involves alternating mechanical deformations and recrystallization anneals. As mechanical deformation progressively modifies the shape of the metal towards that of the final design, work hardening increases to a point where ductility is lost. This can be restored, to facilitate further working, by annealing for a sufficiently long time at a suitable temperature. During such an anneal, the time- and temperature-dependent recrystallization process occurs and the strained microstructure of the metal is replaced by one that is of lower energy and amenable to further deformation.

Recrystallization is a thermally activated phenomenon. It is therefore easier to achieve at high temperatures and is more complete with long holding times at these ternperatures. Also, other things being equal, metals recrystallize more readily (and with finer grains) after heavy deformations than after light working. This behaviour is clearly related to the amount of energy stored during deformation.

Simultaneously with recrystallization, and depending upon the temperature at which it is carried out, a number of other phenomena can take place in multicomponent alloys. Some of these phenomena, such as homogenization of macro- or microsegregations, may be beneficial, but others, such as precipitation of a second phase, may sometimes be highly undesirable. It is therefore of utmost practical importance for the jewellery manufacturer that deformation and annealing schedules of each alloy be accurately defined so as to ensure:

(1) Complete recrystallization which is a prerequisite when further deformation is intended. Normally, this will be achieved by a long soak at high temperature

(2) Small grain size to avoid 'orange peel' effects. This will result from heavy deformations prior to annealing and short soaks at'low temperature
(3) Little or preferably no precipitation of second phase or ordering if the alloy is to be worked after annealing. This can be achieved by annealing at temperatures above the immiscibility or ordering field in the alloy system considered and by efficient quenching from such temperatures.

The above shows that, generally, the annealing temperature and time will be a compromise between, on the one hand, what is desirable in order to achieve complete recrystallization and avoid precipitation of a second phase and, on the other hand, what is desirable to avoid excessive grain size.

Comparatively small variations in alloy compositions can significantly affect the parameters discussed here. It is therefore difficult to define suitable recrystallization schedules for one material from those of another and these schedules are best determined for each alloy composition. It is such an exercise, applied to an 18 carat nickel-containing white gold alloy that is described here. A systematic investigation was carried out of the microstructure of this alloy after increasing cold deformation, following which the results of various annealing conditions were explored until the preferred recrystallization schedule could be determined.

\section{Experimental Conditions}

A commercial alloy, of composition 75 gold/13.1 copper/3.4 zinc/8.5 nickel weight per cent, was the object of the present work. This formulation corresponds to a deliberate choice in favour of ductility and ease of fabrication at the expense of the colour of the alloy (1). Initially, the alloy was cast in ingots approximately $20 \times 100 \times 500 \mathrm{~mm}$ with a mass of 14 to $16 \mathrm{~kg}$.

For the purpose of the investigation, a full cross section of the ingots $(20 \times 100 \mathrm{~mm})$, some $20 \mathrm{~mm}$ thick, was sampled half-way up their height. The ascast alloy was cold-rolled to $10,5,2.5$ and $1.5 \mathrm{~mm}$ 

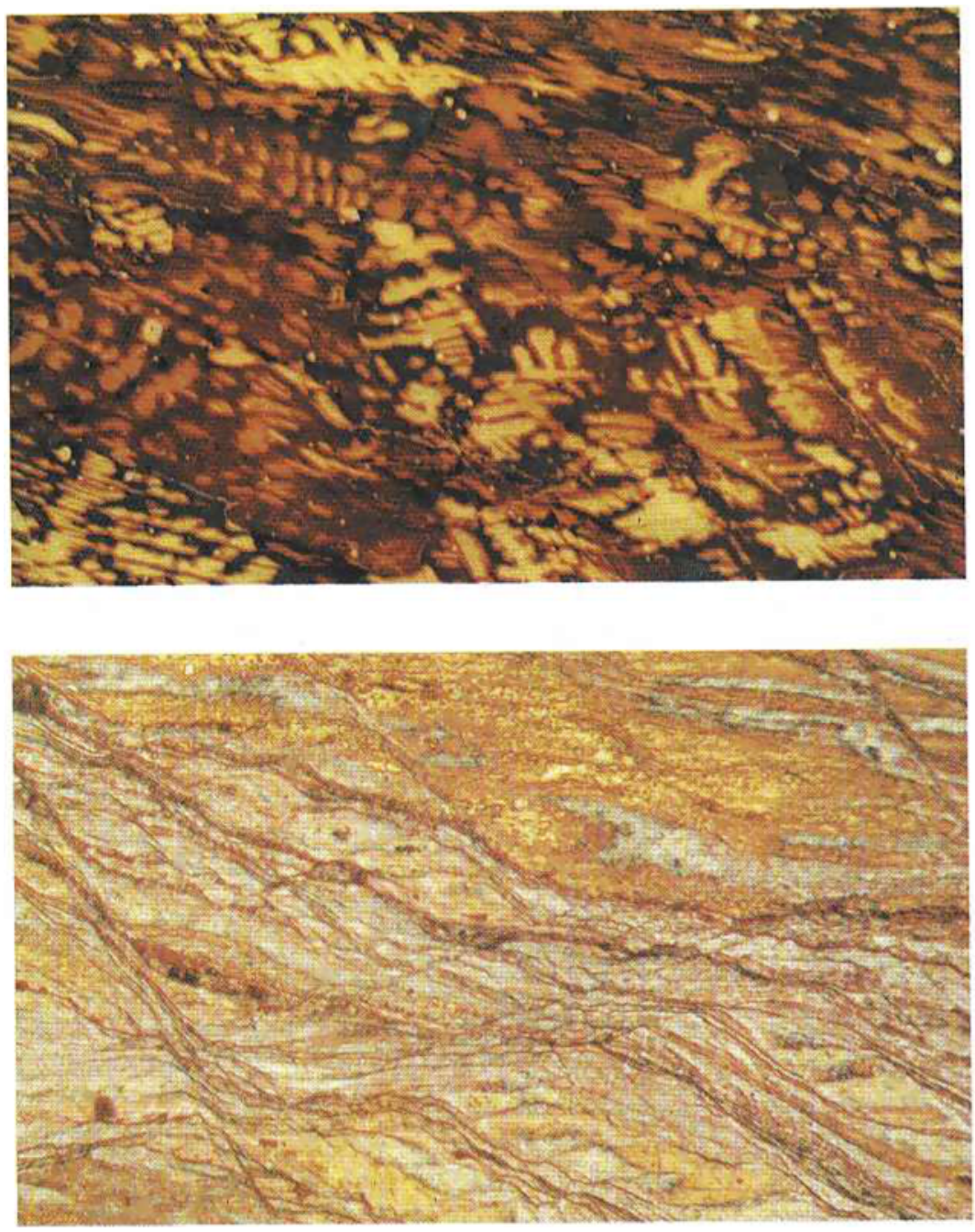

Fig. 1 The dendritic as-cast structure is still visible in this sample of the white gold alloy which was coldrolled 50 per cent $\quad \times 125$

Fig. 2 Lozenge-like pattern and oxidation hues developed on a sample of the white gold alloy after 87.5 per cent cold-rolling from the ascast condition thick, corresponding respectively to cross-section reductions of 50, 75, 87.5 and 92.5 per cent. The rolling direction was parallel to the larger dimension of the original samples.

Metallographic samples of the alloy at various degrees of deformation were prepared and etched by conventional techniques described elsewhere (2). Oxidation hues were developed by very short stays at elevated temperature in air.

Annealing of the alloy was performed in air at temperatures ranging between 420 and $670^{\circ} \mathrm{C}$. A furnace of large thermal inertia was pre-heated to the desired temperature. Under these conditions, the time required for the temperature rise of the small metallographic samples was very short by comparison with the holding time. The alloy was quenched in water from the annealing temperature.

\section{Structure After Cold-Rolling}

After 50 per cent reduction of cross-section by coldrolling, the original grains and dendritic structure of the as-cast alloy were still recognizable (Figure 1). Because stresses applied during rolling affect dif- ferent portions of the microstructure as a function of their crystallographic orientation, dendrites within one single grain were distorted to a varying extent.

After deformations of 75 per cent or more, the original structure was perturbed beyond recognition. In fact, it was replaced by a fibrous network elongated parallel to the rolling direction. The fibres were undulating along a restricted number of directions. Intersection of differently oriented bundles of fibres defined a lozenge-like pattern. The variety of hues developed during oxidation of the surface of the metallographic samples revealed the high state of stress in the material (Figure 2).

At 92.5 per cent deformation, the bundles of fibres were thinner, the sides of the lozenges were rectilinear and their insides consisted of sheaves of fibres. The limited range of oxidation hues revealed that these sheaves were iso-oriented.

All the above features appeared more clearly in the core of the samples than they did closer to the surface which seemed comparatively less strained. This was particularly so for samples deformed in excess of 75 per cent. As could be anticipated, the hardness, 
Fig. 3 Incomplete recrystallization in a sample of the white gold alloy, deformed 50 per cent and annealed 48 hours at $450^{\circ} \mathrm{C}$. Although precipitates of second phase are visible, the phase separation process is also incomplete $\quad \times 650$

Fig. 4 Sample of the white gold alloy annealed 43 hours at $450^{\circ} \mathrm{C}$ after 87.5 per cent deformation. Recrystallization is complete but the banded morphology is strongly reminiscent of that of the deformation pattern

x 1000
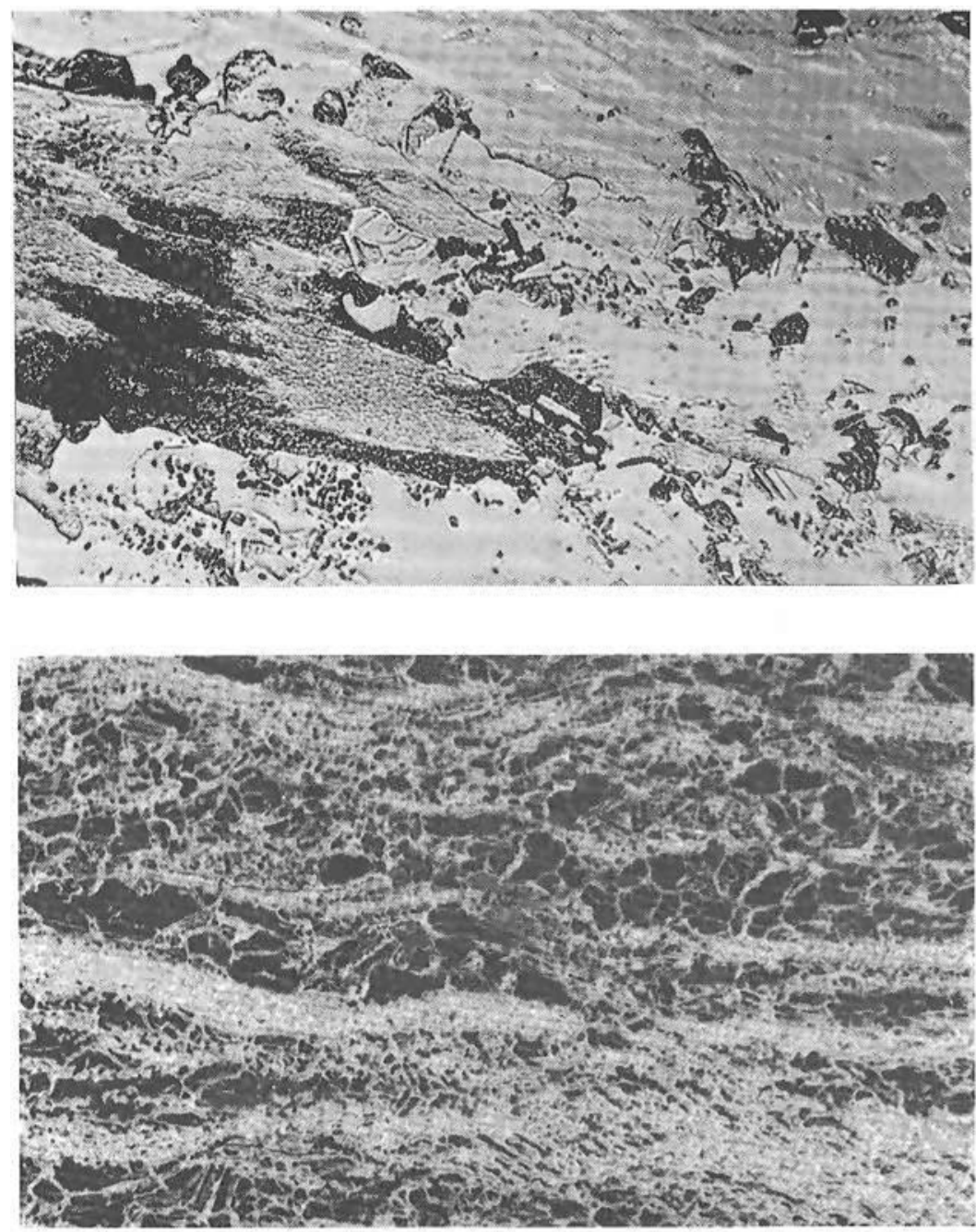

elastic limit and tensile strength of the alloy all increased with the reduction of cross-section.

\section{Structure After Annealing}

Once the effect of cold deformation on the microstructure of the alloy had been established, the next step was to study the effect of annealing time $\left(0.5\right.$ to 48 hours) and temperature $\left(450\right.$ to $\left.670^{\circ} \mathrm{C}\right)$.

\section{Annealing at $450^{\circ} \mathrm{C}$}

After 3 hours at $450^{\circ} \mathrm{C}$ some evidence of recrystallization could be detected by optical microscopy on samples initially deformed 50 per cent. There were few nuclei but these were clearly visible, either at the grain boundaries of the deformed matrix or in highly strained areas. Extending the annealing time increased the amount of recrystallization but even after 48 hours the process remained very incomplete (Figure 3). After 6 hours, lamellar precipitates of second phase were in evidence. Phase separation was found to increase with annealing time. Similar observations were made on samples deformed 75 to 92.5 per cent prior to annealing except that recrystallization was always more advanced for identical annealing conditions. Also, in these samples, second phase precipitates were globular and finely dispersed along the directions defined by the fibres. Complete recrystallization was observed after 29 hours in the samples deformed 92.5 per cent and after 43 hours in those deformed 87.5 per cent. The process was never complete in samples deformed 75 per cent. The structure of fully recrystallized samples was not uniform, being strongly influenced by the fibrous morphology from which it derived. The grains were markedly aligned in strips of different average grain size (Figure 4). Attempts to obtain a more uniform grain size by increased annealing time ( 65 hours) were unsuccessful because of the onset of secondary recrystallization, a process whereby some grains grow larger at the expense of their neighbours.

Monitoring of the hardness of the samples during these experiments (Table I) revealed a sharp drop after 1 hour at $450^{\circ} \mathrm{C}$ when compared with their hardness immediately after cold-working. This was followed, however, after 2 hours by an increase which can be attributed to phase separation (3). 
Table I

Hardness of the 18 Carat Nickel-Containing White Gold Alloy After Annealing at $450^{\circ} \mathrm{C}$ for Inereasing Periods of Time

\begin{tabular}{|c|c|c|c|c|c|c|c|c|c|c|}
\hline \multicolumn{2}{|c|}{$\begin{array}{l}\text { Condition prior } \\
\text { to annealing }\end{array}$} & \multicolumn{9}{|c|}{$\begin{array}{l}\text { Annealing time, hours } \\
\text { Hardness, } \mathrm{H}_{\mathrm{v} 5}\end{array}$} \\
\hline $\begin{array}{l}\text { Deformation } \\
\text { per cent }\end{array}$ & $\begin{array}{l}\text { Hardness } \\
\mathrm{H}_{\mathrm{V} 5}\end{array}$ & 1 & 2 & 3 & 4.5 & 6 & 12 & 29 & 43 & 48 \\
\hline $\begin{array}{l}50 \\
75 \\
87.5 \\
92.5\end{array}$ & $\begin{array}{l}270 \\
302 \\
352 \\
366\end{array}$ & $\begin{array}{l}221 \\
236 \\
249 \\
255\end{array}$ & $\begin{array}{l}255 \\
260 \\
274 \\
273\end{array}$ & $\begin{array}{l}246 \\
244 \\
256 \\
265\end{array}$ & $\begin{array}{l}246 \\
243 \\
255 \\
260\end{array}$ & $\begin{array}{l}239 \\
243 \\
244 \\
252\end{array}$ & $\begin{array}{l}213 \\
220 \\
219 \\
223\end{array}$ & $\begin{array}{c}- \\
\overline{-} \\
240\end{array}$ & $\begin{array}{c}- \\
\overline{-} \\
-\end{array}$ & $\begin{array}{l}232 \\
230 \\
244 \\
275\end{array}$ \\
\hline \multicolumn{11}{|c|}{$\begin{array}{l}\text { Table II } \\
\text { Hardness of the } 18 \text { Carat NickeI-Containing White Gold Alloy After Annealing at } 500^{\circ} \mathrm{C} \text { for } \\
\text { Increasing Periods of Time }\end{array}$} \\
\hline \multicolumn{2}{|c|}{$\begin{array}{l}\text { Condition prior } \\
\text { to annealing }\end{array}$} & \multicolumn{9}{|c|}{$\begin{array}{l}\text { Annealing time, hours } \\
\text { Hardness, } \mathrm{H}_{\mathrm{V} 5}\end{array}$} \\
\hline $\begin{array}{l}\text { Deformation } \\
\text { per cent }\end{array}$ & $\begin{array}{c}\text { Hardiness } \\
H_{v 5}\end{array}$ & 1.5 & 3 & 4.5 & 6 & 9 & 12 & 18 & 24 & 48 \\
\hline $\begin{array}{l}50 \\
75 \\
87.5 \\
92.5\end{array}$ & $\begin{array}{l}270 \\
302 \\
352 \\
366\end{array}$ & $\begin{array}{l}225 \\
223 \\
252 \\
228\end{array}$ & $\begin{array}{l}229 \\
235 \\
247 \\
240\end{array}$ & $\begin{array}{l}233 \\
252 \\
242 \\
255\end{array}$ & $\begin{array}{l}237 \\
251 \\
234 \\
249\end{array}$ & $\begin{array}{l}239 \\
226 \\
232 \\
257\end{array}$ & $\begin{array}{l}220 \\
227 \\
241 \\
231\end{array}$ & $\begin{array}{l}- \\
\overline{-} \\
\overline{240}\end{array}$ & $\begin{array}{c}- \\
\overline{216} \\
-\end{array}$ & $\begin{array}{c}215 \\
233 \\
- \\
-\end{array}$ \\
\hline
\end{tabular}

Table III

Hardness of the 18 Carat Nickel-Containing White Gold Alloy $\Lambda$ fter Annealing at $670^{\circ} \mathrm{C}$ for Increasing Periods of Time

\begin{tabular}{|c|c|c|c|}
\hline \multicolumn{2}{|c|}{$\begin{array}{l}\text { Condition prior } \\
\text { to annealing }\end{array}$} & \multicolumn{2}{|c|}{$\begin{array}{l}\text { Annealing time, hours } \\
\text { Hardness, } \dot{H}_{v_{5}}\end{array}$} \\
\hline $\begin{array}{c}\text { Deformation } \\
\text { per cent }\end{array}$ & $\begin{array}{l}\text { Hardness }_{x} \\
\mathrm{H}_{\mathrm{V} 5}\end{array}$ & 0.5 & \\
\hline $\begin{array}{l}50 \\
75 \\
87.5 \\
92.5\end{array}$ & $\begin{array}{l}270 \\
302 \\
352 \\
366\end{array}$ & $\begin{array}{l}197 \\
198 \\
196 \\
194\end{array}$ & $\begin{array}{l}192 \\
190 \\
193 \\
195\end{array}$ \\
\hline
\end{tabular}

It can be concluded that, irrespective of the amount of initial deformation, annealing around $450^{\circ} \mathrm{C}$ is not advisable for the alloy investigated here. Furthermore, even short stays at this temperature should be carefully avoided during industrial processing.

\section{Annealing at $500^{\circ} \mathrm{C}$}

The effects depicted after annealing at $450^{\circ} \mathrm{C}$ were again observed after annealing at $500^{\circ} \mathrm{C}$. They were, however, significantly accelerated and both recrystallized grains and second phase precipitates were visible after 1 hour at temperature in samples deformed 50 per cent only. Again, complete recrystallization did not occur after 48 hours. This was achieved only in samples deformed 75 per cent or more and was characterized by a banded appearance, although this was less marked than in samples recrystallized at $450^{\circ} \mathrm{C}$. Prolonged annealing led to secondary recrystallization without improvement in the homogeneity of the grain size (Figure 5).
Phase separation at $500^{\circ} \mathrm{C}$ was found to be more abundant in the heavily deformed samples. The pattern of hardness changes with annealing time (Table II) was similar to that reported in Table I.

\section{Annealing at 650 to $670^{\circ} \mathrm{C}$}

Half an hour at $650^{\circ} \mathrm{C}$ was found sufficient to result in complete recrystallization of samples initially cold-rolled 75 per cent or more. Some remnants of the deformation structure were still observed in samples deformed 50 per cent only. In all cases, the grains in the recrystallized alloy were equiaxed and homogeneous in size for a given reduction rate. The average grain diameter tended to decrease as the extent of deformation of the samples prior to annealing was increased from 50 to 92.5 per cent but it was always larger than that observed after annealing at lower temperature of the same type of sample. Oxidation hues revealed that there was still a relationship between the orientation of the recrystallized structure and that of the initially deformed matrix.

Extending the annealing time to 2 hours further improved the shape of the grains and resulted in a recrystallized structure without obvious relationship with that of the pre-existing deformation fibres (Figure 6).

Phase separation could not be detected in any of the samples annealed at 650 to $670^{\circ} \mathrm{C}$ and quenched from this range. This observation was supported by the fact that the hardness of all samples was very much lower (Table III) than that recorded after annealing at lower temperature. 
Fig. 5 Evidence of secondary recrystallization in a sample of the white gold alloy, deformed 87.5 per cent and annealed 30 hours at $500^{\circ} \mathrm{C}$ $\times 1000$

Fig. 6 Ideal recrystallized structure of a sample of the white gold alloy, deformed 92.5 per cent and annealed 2 hours at $670^{\circ} \mathrm{C}$
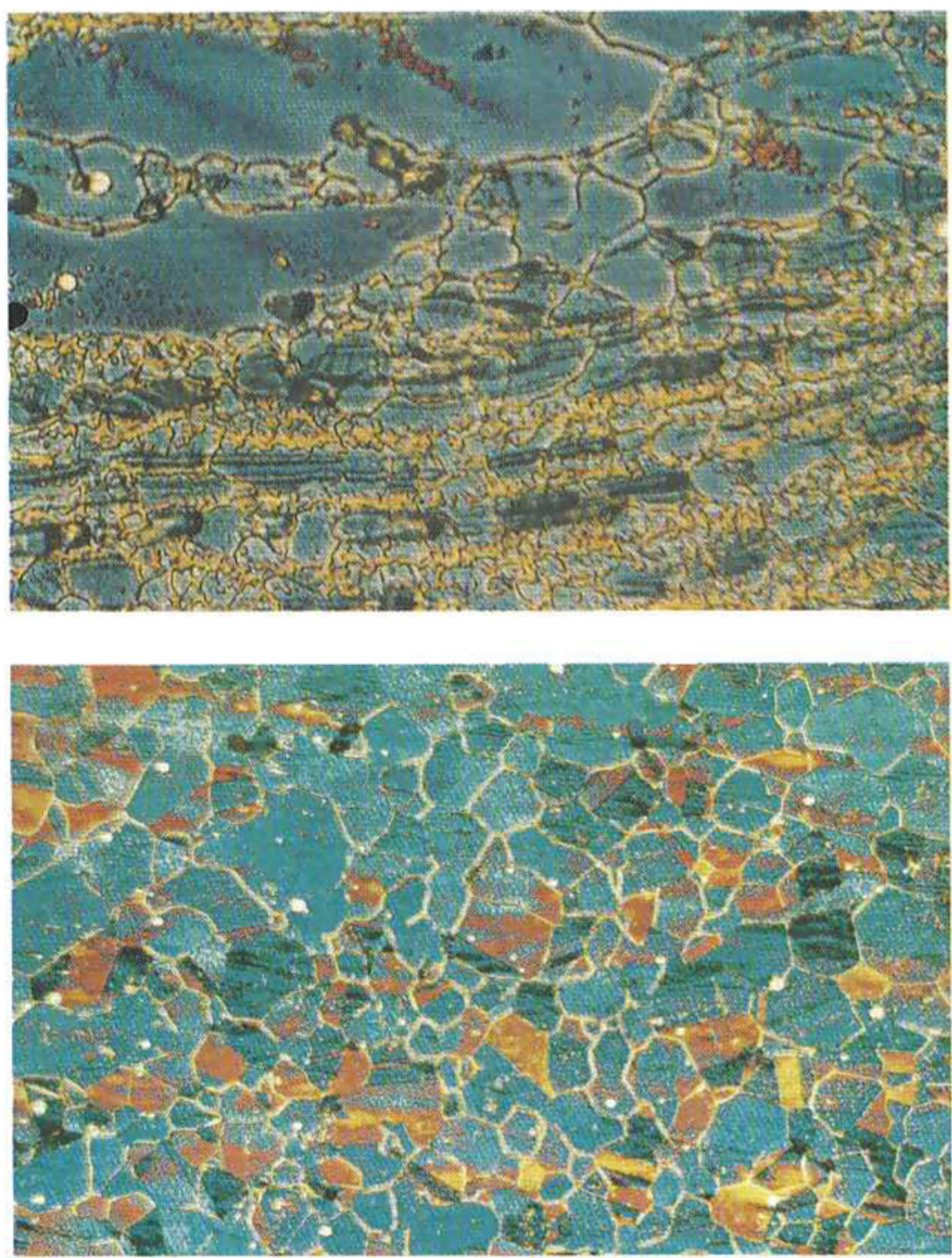

\section{Conclusions}

Recrystallization of a 75 gold/13.1 copper/3.4 zinc/8.5 nickel weight per cent alloy deformed 50 to 92.5 per cent by cold rolling begins at temperatures as low as $450^{\circ} \mathrm{C}$. Irrespective of the annealing temperature, the times at temperature necessary to both initiate and complete recrystallization are strongly dependent on the degree of pre-deformation and are lowest for samples deformed 92.5 per cent. When the annealing times at 450 or $500^{\circ} \mathrm{C}$ are such as to cause complete recrystallization, the structure consists of alternating fine- and coarse-grained bands related to the fibrous deformation structure. Improvements in this respect are not brought about by extending the annealing time. The latter practice can even lead to secondary recrytallization whereby some grains show excessive growth. In parallel with recrystallization, separation of a second phase takes place in the temperature range 450 to $500^{\circ} \mathrm{C}$ with the overail result that the hardness of the annealed alloy is higher than is desirable for further processing.
Annealing in the temperature range 650 to $670^{\circ} \mathrm{C}$ achieves complete recrystallization in about 1 hour or less, depending upon the percentage of predeformation and produces equiaxed structures. Samples quenched from this temperature range show no phase separation. Their comparatively low hardness renders them suitable for further processing as required. Thus, in industrial practice, an acceptable recrystallization schedule for this 18 carat nickelcontaining white gold alloy is to heat it for 1 hour at 650 to $670^{\circ} \mathrm{C}$ and to quench it in water thereafter.

\section{Acknowledgements}

The authors thank the firm Gori \& Zucchi of Arezzo, Italy, for sponsorship of this work and for the supply of alloy samples. Thanks are also due to Dr. O. Caloni of Gori \& Zucchi, for his interest and assistance in this study.

\section{References}

1 A. S. McDonald and G. H. Sistare, Gold Bull., 1978, 11, (4), 128-131

2 E. Stagno and M. R. Pinasco, Mém. Sci. Rev. Métall., 1976, 73 (1), 35-55

3 E. Stagno and M. R. Pinasco, work in progress, to be published 